\title{
Ca-SUBSTITUTED POLYCRYSTALLINE GARNETS WITH VERY LOW OPTICAL ABSORPTION
}

\author{
S. SHIMANUKI, S. NOMURA, and T. YAMASHITA \\ Toshiba Research and Development Center, Kawasaki 210, Japan
}

ABSTRACT

Ca-substituted polycrystalline garnets with low optical absorption coefficient, below $2 \mathrm{~cm}^{-1}$, can be reproducibly prepared by reducing the cause of dispersion and absorption. The lowest optical absorption coefficient which has been measured so far is $0.5 \mathrm{~cm}^{-1}$ at the wavelength of 1.55 $\mu_{\mathrm{m}}$. Reduction of porosity can be accomplished by simultaneous substitution of $\mathrm{Y}^{3+}$ ions by $\mathrm{Ca} 2+i$ ons in combination with $\mathrm{v}^{5+}$ ions for charge compensation and by sintering near the temperature at which the anomalous grain growth originates. Also, heat treatment at the temperature in the normal grain growth region reduces optical absorption of CaV-substituted polycrystalline garnets. It was found that the dispersion effect on optical absorption caused by grains is small in comparison with the dispersion caused by pores.

\section{INTRODUCTION}

Rare-earth iron garnets single crystals with low optical absorption and large Faraday rotation in the infrared region have been investigated for uses as Faraday rotators making up optical isolators for fiber-optic communication and fiber-optic magnetic field sensors [1], [2]. On the other hand, polycrystalline garnets have been mainly used for microwave applications required for narrow resonance linewidths. Polycrystalline garnets have, in general, large optical absorption in comparison with single crystal garnets, since a large number of pores and grains are contained inside polycrystalline samples. Therefore, polycrystalline garnets have not been considered suitable for optical applications.

Ca-substituted polycrystalline garnets, however, are known to become very dense and show narrow resonance linewidths in the microwave region [3]. As a consequence of complete absence of porosity and phase impurity, polycrystalline garnets may become transparent in the infrared "window" region (about 1.1 to $5 \mu \mathrm{m}$ wavelength). However, the optical absorption coefficient for Ca-substituted polycrystalline garnets ( $\mathrm{Ca} \cdot \mathrm{In} \cdot \mathrm{Ge}-\mathrm{Y}$ IG) reported so far is higher than that for $Y 1 \mathrm{G}$ single crystals. The values are about $10 \mathrm{~cm}-1$ [4]. The factors limiting transparency in polycrystalline materials are thought to be pores, second phase and grain boundaries. The effects of pores, grain size and second phases on transparency for Ca-substituted polycrystalline garnets have not yet been investigated in detail.

In this work, we report the effects of porosity, grain size, $V$ content, sintering temperature, heat treatment and hot-pressing on optical absorption coefficients in CaV-substituted polycrystailine garnets $\left(\left\{\mathrm{Y}_{3-2 \mathrm{x}} \mathrm{Ca}_{2 \mathrm{x}}\right\}\left[\mathrm{Fe}_{2}\right]\left(\mathrm{Fe}_{3-\mathrm{x}} \mathrm{V}_{\mathrm{X}}\right) \mathrm{O}_{12}\right)$ in order to obtain polycrystalline garnet with very low optical absorption suitable for optical applications.

\section{EXPERIMENTAL}

Polycrystalline samples, with $\mathrm{x}=0.05,0.10$ and $\mathrm{x}=0.30$ in CaV-substituted garnets $\left(\left\{\mathrm{Y}_{3-2 \mathrm{x}} \mathrm{Ca}_{2 \mathrm{x}}\right\}\right.$ [Fe $\left.\left.{ }_{2}\right]\left(\mathrm{Fe}_{3-\mathrm{x}} \mathrm{V}_{\mathrm{X}}\right) \mathrm{O}_{12}\right)$, were prepared by the usual ceramic sintering technique. The raw materials $\mathrm{Y}_{2} \mathrm{O}_{3}$ (>99.99 percent), $\mathrm{CaCO}_{3}, \mathrm{Fe}_{2} \mathrm{O}_{3}$ and $\mathrm{V}_{2} \mathrm{O}_{5}(\geq 99$ percent) were mixed in a steel ball mill and prefired at $1000-1100^{\circ} \mathrm{C}$ in an oxygen atmosphere for 4 to 8 hours. The final sintering was carried out at $1350-1550^{\circ} \mathrm{C}$ (in addition to being annealed at $1300-1400^{\circ} \mathrm{C}$ ) in an oxygen atmosphere for $0.5-8$ hours. Polycrystalline samples were carefully prepared in composition with an accuracy of \pm 0.1 wt\% to obtain stoichiometric samples without second phase (hematite, orthoferrite etc.). $\bar{X}$-ray analysis was used to measure lattice parameter $a$ and confirm whether or not the desired single garnet phase has been prepared. Grain sizes, pores and second phases were examined by an optical microscope and a scanning electron microscope (SEM). Relative density of samples was determined from X-ray density and water displacement densitometry. Optical absorption measurements were carried out on mirror polished samples, $0.1-1.0 \mathrm{~mm}$ thick, using an optical power meter (Anritsu ML910A) with a laser diode $(\lambda=1.55 \mu \mathrm{m})$ in a saturating magnetic field up to 4 k0e. Faraday rotation with the applied field up to $4 \mathrm{kOe}$ was measured by a usual extinction method, using an optical power meter, a laser diode $(\lambda=1.55 \mu \mathrm{m})$ and a Glan-Thompson prism with an optical encoder, with +0.1 degree accuracy. The optical absorption coefficient $(\alpha)$ was calculated from the transmission $(T)$ and reflection losses (R) by the Lambert-Beer law

$$
T=(1-R)^{2} e^{-\alpha t} /\left(1-R^{2} e^{-2 \alpha t}\right)
$$

where $t$ is sample thickness. 


\subsection{MICROSTRUCTURE}

Figure 1 shows relative density and average grain size for $\mathrm{Y}_{2.9} \mathrm{Ca}_{0.1} \mathrm{Fe}_{4.95} \mathrm{~V}_{0.05} \mathrm{O}_{12}$ as a function of sintering temperature in the temperature range $1440-1550^{\circ} \mathrm{C}$ (sintering time was 8 hours). The relative density increases with increasing sintering temperature, up to $1500 \mathrm{C}$, and reaches about $100 \%$ (with $\pm 0.2 \%$ accuracy), equal to the theoretical density ( $X$-ray density) calculated by the lattice parameter. The relative density becomes constant in the temperature range $1500-1520^{\circ} \mathrm{C}$ and then slightly decreases with increasing sintering temperature beyond $1520^{\circ} \mathrm{C}$. Consequently, in the temperature range $1500-1520{ }^{\circ} \mathrm{C}$ polycrystalline samples with high density were obtained. The grain size rapidly increases from 6 to $40 \mu \mathrm{m}$ with increasing sintering temperature in the temperature range $1440-1500^{\circ} \mathrm{C}$ and then rapidly decreases to $8 \mu \mathrm{m}$ through $1500^{\circ} \mathrm{C}$. In the former temperature range (below $1500^{\circ} \mathrm{C}$ ) grains grow by the normal grain growth (indicated by open marks). To the contrary, in the latter temperature (over $1500^{\circ} \mathrm{C}$ ) grains grow by the so-called anomalous grain growth. In this anomalous grain growth region (indicated by closed marks), huge grains (so-called anomalous grains) a few $\mathrm{mm}$ in diameter is observed in the matrix consisting of small grains when samples were sintered for over 2 hours. The average grain size indicated in Figure 1 was measured from these small grains in the matrix except for huge grains. This average grain size hardly change for sintering time. In polycrystalline samples of $\mathrm{Y}_{2.9} \mathrm{Ca}_{0.1} \mathrm{Fe}_{4.95} \mathrm{~V}_{0.05} \mathrm{O}_{12}$

with $100 \%$ density, pores were very $f e w$ or were rarely observed inside the sample as shown in fractographs in Figures 2 and 3 , in the normal and anomalous grain growth regions, respectively. Figures 4 and 5 show microstructures of the high density sample and the sample with a large number of pores, respectively. Generally, non-substituted polycrystalline garnets (YIG) contain a large number of pores inside the grains and the grain boundaries. To the contrary, in Ca-subsitituted polycrystalline garnets with pores, almost pores remain in the grain boundaries as shown in Figure 5. These situations were similarly observed in other compositions, with $\mathrm{rich} V$ content ( $x=0.10$ and $x=0.30)$. The reason for high density Ca-substituted polycrystalline garnets is thought to be that the grain growth rates is slower than the rate for elimination of pores, whereas a contrary situation exists for YIG polycrystalline samples. In particular, in the anomalous grain growth, since the grain growth rate becomes extremely slow, polycrystalline samples are highly densified. Densification and small grains in the anomalous grain growth region are due to the phenomenon wherein the grain growth stops due to the existence of a small amount of liquid phase. The huge grain grows from the matrix of small grain over $1500^{\circ} \mathrm{C}$. The driving force of growth is thought to be proportional to the reciprocal diameter of grain. Therefore, the grain size is smaller and the growth rate for huge grains is faster. It is expected that these densified Ca-substituted polycrystalline garnets will possess low optical absorption.

\subsection{OPTICAL PROPERTIES}

Figure 6 shows optical absorption for $\mathrm{Y}_{2} .9 \mathrm{Ca}$ $0.1^{\mathrm{Fe}} 4.95^{\mathrm{V}} 0.05^{\circ} \mathrm{O}_{12}$ as a function of sintering temperature. The optical absorption decreases
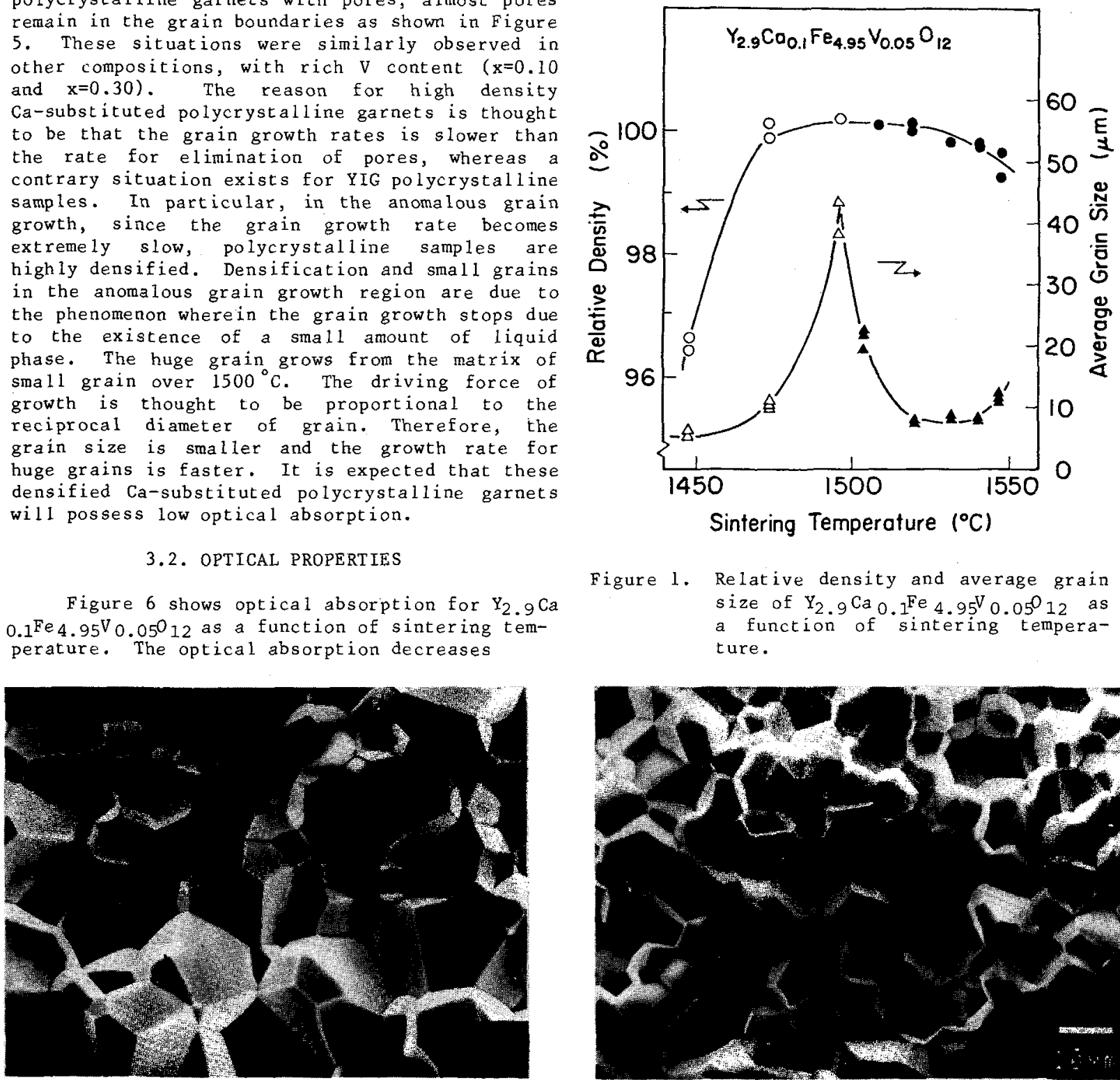

Figure 1. Relative density and average grain size of $\mathrm{Y}_{2.9} \mathrm{Ca}_{0.1} \mathrm{Fe}_{4.95^{\mathrm{V}} 0.05^{\mathrm{O}} 12 \text { as }}$ a function of sintering temperature.

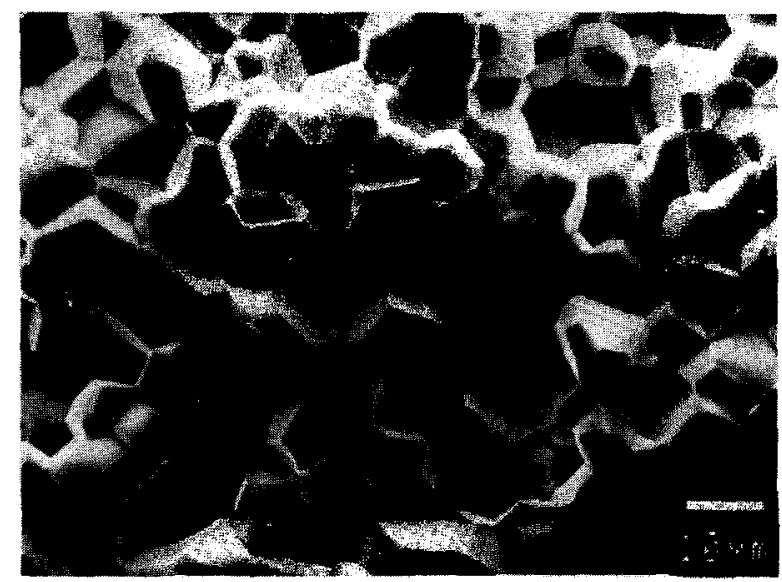

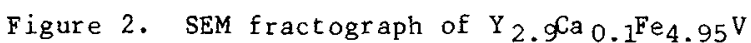
$0.05^{\circ} 12$ with high density in the normal grain growth region.

Figure 3. SEM fractograph of $\mathrm{Y}_{2.9} \mathrm{Ca}_{0} .{ }_{1} \mathrm{Fe}_{4.95} \mathrm{~V}$ $0.05 \mathrm{O}_{12}$ with high density in the anomalous grain growth. 


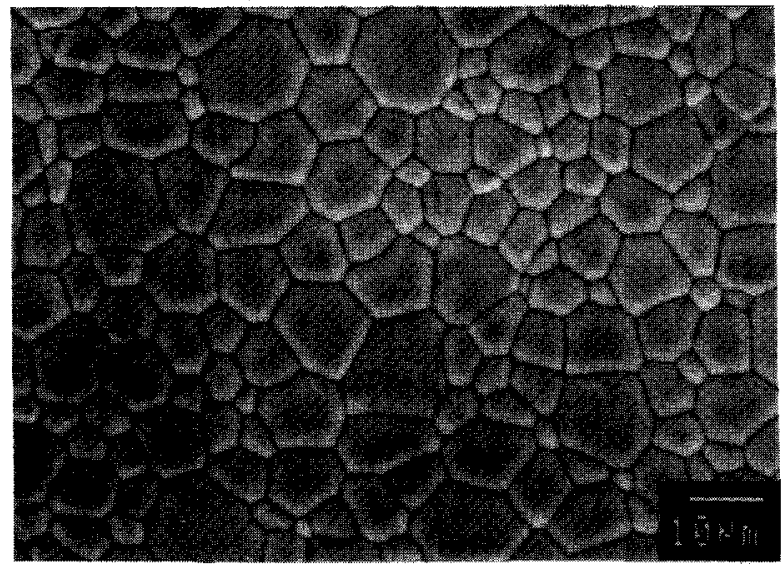

Figure 4. Microstructure of $\mathrm{Y}_{2.9} \mathrm{Ca}_{0.1} \mathrm{Fe}_{4.95} \mathrm{~V}$

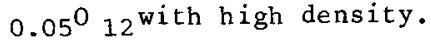

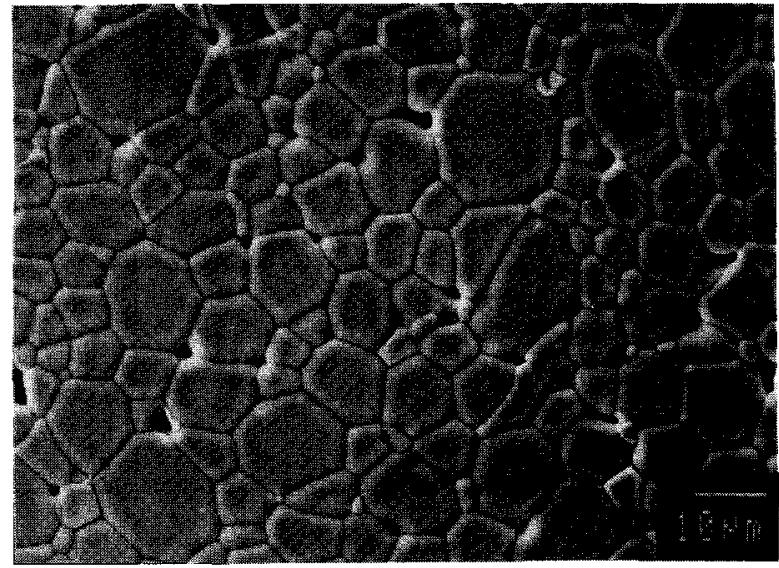

Figure 5. Microstructure of $\mathrm{Y}_{2.9}{ }^{\mathrm{Ca}} 0.1^{\mathrm{Fe}} 4.95^{\mathrm{V}}$ $0.05^{0} 12$ with a large number of
pores.

with increasing sintering temperature, and shows a minimum value near the temperature of $1500^{\circ} \mathrm{C}$, in which the density becomes maximum as shown in Figure l. In the temperature range $1490-1520^{\circ} \mathrm{C}$, optical absorption coefficients below $2 \mathrm{~cm}^{-1}$ can be reproducibly obtained in Y2.9Ca0.1Fe4.95V0.05 $0_{12}$ polycrystalline garnets. The lowest value of optical absorption coefficient is $0.5 \mathrm{~cm}-1$ at the wavelength of $1.55 \mathrm{\mu m}$. This shows that suppression of porosity remarkably reduces optical absorption. Also, optical absorption coefficients in the compositions of high $V$ content become large in comparis on with $\mathrm{Y}_{2.9} \mathrm{Ca}_{0.1} \mathrm{Fe}_{4} .95 \mathrm{~V} 0.05 \mathrm{O}_{12}$. Optical absorption coefficients for $\mathrm{Y}_{2.8} \mathrm{Ca}_{0.2}$ Fe4.9V0.10 12 polycrystalline garnets are about $2.6 \mathrm{~cm}-1$ as shown in Table 1 . Optical absorption coefficients for $\mathrm{Y}_{2} .4 \mathrm{Ca}_{0} .6 \mathrm{Fe} 4.7 \mathrm{~V}_{0} .3 \mathrm{O}_{12}$ are large $\left(\alpha>100 \mathrm{~cm}^{-1}\right)$ by the existence of a small amount of second phases. This high optical absorption coefficient for high $V$ content samples seems to be due to the reason that the garnet single phase region becomes narrow with increasing $V$ content and stoichiometric samples with no second phase can't be easily obtained. A large amount of substitution of $\mathrm{V}^{5+}$ ions may give no advantage.

Figure 7 shows optical absorption of $\mathrm{Y} 2.9 \mathrm{Ca} 0.1 \mathrm{Fe} 4.95 \mathrm{~V} 0.05012$ as a function of grain size in the normal (open circle) and anomalous (closed circle) grain growth regions. In the normal grain growth region, small grain samples have high optical absorption since they contain pores as shown in $\mathrm{F}$ igure 1. However, in the anomalous grain growth region, small grain samples have low optical absorption which is similar to that for large grain samples in the normal grain growth region. That is, the effect of grain size on optical absorption is small and it is estimated that the increase in optical absorption coefficient due to grain size is below 1 to $2 \mathrm{~cm}^{-1}$. Polycrystalline samples sintered in the anomalous grain growth region in Figures 6 and 7 are usually annealed in the normal grain growth region. However, unannealed samples show high optical absorption owing to ferrous ions. The optical absorption coefficient of $6 \mathrm{~cm}^{-1}$ for the sample,

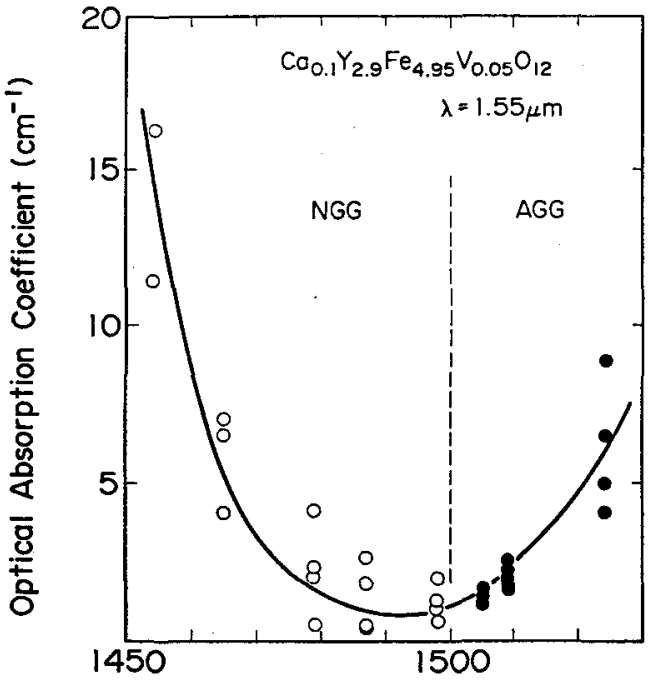

Sintering Temperature $\left({ }^{\circ} \mathrm{C}\right)$

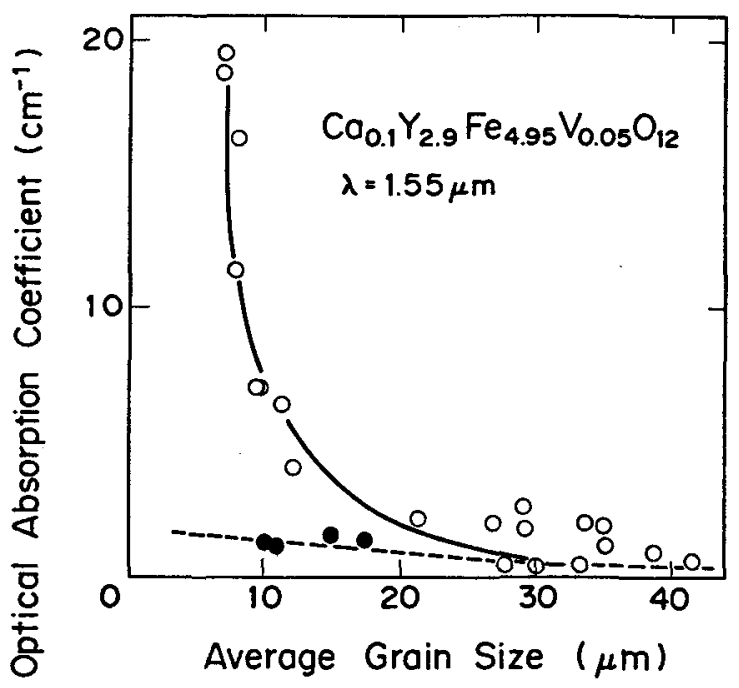

Figure 6. Optical absorption coefficient of $\mathrm{Y}$ $2 . \mathrm{Ca}_{0.1} \mathrm{Fe} 4.95^{\mathrm{V}} 0.05^{\circ} 12$ as a func-

Figure 7. Optical absorption coefficient of $\mathrm{Y}$ $2,{ }_{9} \mathrm{Ca}_{0.1} \mathrm{Fe}_{4.95} \mathrm{~V}_{0.05^{\circ}}{ }_{12}$ as a function of grain size in the normal and anomalous grain growth regions. 
TABLE 1. Optical absorption coefficients $(\lambda=1.55 \mu \mathrm{m})$ for polycrysta1line samples in CaV-substituted garnets.

\begin{tabular}{ccccc}
\hline $\begin{array}{c}\text { Composition } \\
{[\mathrm{X}]}\end{array}$ & Density $[\mathrm{g} / \mathrm{cm}]$ & $\left.\begin{array}{c}\text { Minimum } \\
\text { values of } \\
\alpha\end{array} \mathrm{cm}^{-1}\right]$ & $\begin{array}{c}\text { Grain size } \\
{[\mu \mathrm{m}]}\end{array}$ & Grain growth region \\
\hline 0.05 & 5.13 & 0.5 & 33 & NGG \\
0.05 & 5.13 & 1.6 & 8 & AGG \\
0.10 & 5.09 & 2.6 & 10 & AGG \\
\hline
\end{tabular}

NGG and AGG show that samples were sintered in the normal and anomalous grain growth regions, respectively.

sintered at $1520^{\circ} \mathrm{C}$ in the anomalous grain growth region, is reduced to about $1 \mathrm{~cm}^{-1}$ by annealing at $1400^{\circ} \mathrm{C}$ for 2 hours in the normal grain growth region. Hot-pressing reduces optical absorption for porous polycrystalline garnets. The optical absorption coefficient of $45 \mathrm{~cm}^{-1}$ is reduced to $9 \mathrm{~cm}^{-1}$ by hot-pressing in the temperature range $1430-1500^{\circ} \mathrm{C}$ (about $100 \mathrm{~kg} / \mathrm{cm}^{2}$ ). Also, the Faraday rotation for $\mathrm{Y}_{2.9} \mathrm{Ca}_{0.1} \mathrm{Fe}_{4} .95 \mathrm{~V}_{0.05} \mathrm{O}_{12}$ with low optical absorption is about $170^{\circ} / \mathrm{cm}$. These highly densified polycrystalline garnets can be transformed to single crystals by solid phase reaction using seeds [5].

\section{CONCLUSION}

By suppressing of pores it is possible to reproducibly obtain CaV-substituted polycrystalline garnets with a very low optical absorption coefficient, below $2 \mathrm{~cm}^{-1}$. The lowest optical absorption coefficient, which have been measured so far, is $0.5 \mathrm{~cm}^{-1}$ at $1.55 \mu \mathrm{m}$ in $\left\{\mathrm{Y}_{2.9} \mathrm{Ca}_{0.1}\right\}\left[\mathrm{Fe}_{2}\right]$ ( Fe 2.95 V0.05) 012 polycrystalline garnets. Low optical absorption can be realized with high densified samples sintered near the temperature at which the anomalous grain growth originates. The reason for this is that since the grain growth rate is slower than the elimination rate of pores, pores in the samples are reduced. Also, heat treatment at the temperature in the normal grain growth region and hot-pressing reduce optical absorption for polycrystalline samples.

These low optical absorption polycrystalline garnets are promising for uses as Faraday rotation materials in fiber optic magnetic field sensors and other magneto-optical devices.

\section{REFERENCES}

1. H. Iwamura, S. Hayashi and H. Iwasaki : Opt. Quantum Electron. 10, 393 (1978)

2. G.A. Massey, D.C. Ericks on and R.A. Kadlec : Appl. Optics. 14, 2712 (1975)

3. H.J. Van Hook, J.J. Green, F. Euler and E.R. Czerlinsky : J. Appl. Phys. 39, 730 (1968)

4. G. Winkler : IEEE Trans. Magn. MAG-7, 773 (1971)

5. S. Nomura, S. Shimanuki and T. Yamashita : International Symposium on Magneto-optics, Kyoto Japan, 21 B-02 (1987) 